\title{
EFFICACY OF PLATELET RICH FIBRIN PREPARED WITH TITANIUM TUBES AND PLATELET RICH FIBRIN PREPARED WITH PLASTIC TUBES IN SOFT TISSUE WOUND HEALING: AN EXPERIMENTAL STUDY IN SHEEP.
}

\author{
JiYAR M. NAJI and OMAR HAMEED. \\ Dept. of Oral Surgery, College of dentistry, University of Duhok, Kurdistan Region- Iraq.
}

(Received: October 14, 2019; Accepted for Publication: November 28, 2019)

\begin{abstract}
We have used a developed new titanium-prepared, platelet-rich fibrin (T-PRF) with the protocol for making it, which is established on the hypothesis that titanium tubes may be more effective at activating platelets than the glass tubes used by Chouckroun in his platelet-rich fibrin (PRF) method (tunali et al 2013). The aim of this study was to investigate the efficacy of T-PRF and compare with L-PRF for soft tissue wound healing. Blood samples from 10 sheep were used to confirm the protocol for formation of $T$ PRF and L-PRF to develop the experiment. The mucoperiosteal flaps were filled with autologous T-PRF membranes and L-PRF in the mandible and maxillary regions.

Samples collected from the surgical sites were stained with haematoxylin and eosin. We found that after 14 days of membranes implantation there was no significant differences between there histological sections. While in histological section of 28 days, the PRF prepared with titanium tube has effect in soft tissue with much and more organized collagen and less inflammatory cells reaction in compare with PRF prepared with plastic tubes effect in soft tissue wound healing. Both tubes had been centrifuged for $\mathbf{1 5}$ min at $3500 \mathrm{rpm}$.
\end{abstract}

KEYWORDS: titanium tubes, platelet rich fibrin, plastic tubes.

\section{INTRODUCTION}

B lood is a mixture of plasma, various types of cell, and platelets (biologicallyactive cellular fragments). Thrombocytes have a significant role in coagulation, and inhibit excessive blood loss in venous injuries. They contain numerous cytokines and growth factors that affect bony regeneration and maturation of soft tissue (Anitua et al 2006) Platelet-derived growth factorAB(PDGF-AB), transforming growth factor_- 1 (TGF_-1), and vascular endothelial growth factor (VEGF) are key growth factors that are present in thrombocytes.

Platelet-rich fibrin (PRF) was first developed in France by Choukroun in 2001 as an autologous biomaterial that contains leucocytes and platelet-rich fibrin(PRF) (Choukroun $J$ et al 2001) .Unlike other platelet-rich products, the technique necessitates neither anticoagulant nor bovine thrombin (or any other gelling agent) (Dohan DM, Choukroun, Rasmusson L et al
2009) .Successful clinical results have been reported with PRF,( Dohan ,Choukroun ,Rasmusson et al 2009) but some physicians (O'Connell 2007) worry about a possible health threat as it uses glass-evacuated collection tubes for the blood with silica activators. O'Connell defined the unavoidable contact with silica. These particles of silica in the tube, although they are dense enough to sediment with the red blood cells, are small enough for an element to remain suspended colloidally in the buffy coat, fibrin, and platelet-poor layers of plasma. The particles might then reach the patient when the product is used for treatment.

Titanium-prepared, platelet-rich fibrin ( $\mathrm{T}$ PRF) is a new platelet concentrate, the method of preparation of which is based on the hypothesis that titanium tubes may be more effective in activating platelets than the glass tubes used in Chouckroun's method. (Adda, Diss, Choukroun et al 2006) This material is used to prevent any adverse effects in the short 
or long term, or both, of dry glass or glasscoated plastic tubes and to exclude any speculations about silica. In their initial trials, they found titanium- induced platelet aggregation similar to that in glass tubes, and the clot produced in titanium tubes was clinically matching to that produced in glass tubes. Activation of platelets with titanium compared with activation with silica particles provides the distinctive characteristics of T-PRF, including its improved biocompatibility.

The T-PRF collection protocol in human subjects is similar to the conventional PRF protocol as follows (Dohan et al 2006). A blood sample is collected without anticoagulant in 10 $\mathrm{ml}$ titanium tubes, that are immediately centrifuged at $3500 \mathrm{rpm}$ for $15 \mathrm{~min}$. The absence of anticoagulant involves that most platelets in the blood sample will be activated within a few minutes after contact with the wall of the titanium tube, which initiates the coagulation cascade. Fibrinogen is primarily concentrated in the upper part of the tube before the circulating thrombin transforms it into fibrin. A fibrin clot is then formed in the middle of the tube between the red corpuscles at the bottom and the acellular plasma at the top (Dohan Et al 2006). Many studies are necessary to evaluate a newly developed T-PRF product carefully. In vivo animal experiments are needed before its use in humans, so that we can fully understand the potential role that it may have in wound healing. However, conventional clinical studies on PRF have usually been done in humans (Choukroun ,Simonpieri, Del Corso et al 2009) . There have been several recent studies using cells in vitro (Huang FM, Doglioli P et al 2010) and even fewer animal studies reported (Lee E-H et al 2010). Serious criticisms have been brought to light regarding the studies of PRF in animals (Dohan et al 2010) The objective of this study was to investigate the effectiveness of T-PRF in compare with L-PRF in vivo on soft tissue wound healing.

\section{MATERIAL AND METHODS}

The study was conducted on ten adult local breed male sheep (rams), their age ranged between (10-12) months and their body weight ranged from (31-55) kg.

The rams were housed indoors in concrete stalls in the animals' farm of the college of veterinary medicine/Dohuk university two weeks before surgery to become accustomed to the farm condition. The rams were subjected to a thorough clinical examination and complete blood examination to ascertain their health status. They were assessed to be free of diseases and healthy. The study was approved by ethical committee of Dohuk university.

The rams were allowed free access to hay and water. Barley was administered twice daily. The animals were identified with numbered plastic ear tags.

Preparation of T-PRF and L-PRF membranes and operations

After the T-PRF and L-PRF clot that were most suitable for use was clinically established (centrifugation at $3500 \mathrm{rpm}$ for $15 \mathrm{~min}$ ) (tunali 2013) blood samples from 10 rams were used for the T-PRF and L-PRF operations.

Food was withheld from the rams for 36 hours and water for 12 hours before the operation. The skin over one side of the face (over the nasal, maxillary, and mandibular bones) was prepared aseptically by clipping, shaving and application of povidone iodine.

Blood was rapidly collected and immediately centrifuged at $3500 \mathrm{rpm}$ for $15 \mathrm{~min}$. After centrifugation, clots were removed from the tubes using sterile tweezers, separated from the base of red blood cells (RBC), and pressed between two pieces of gauze fig (1). 


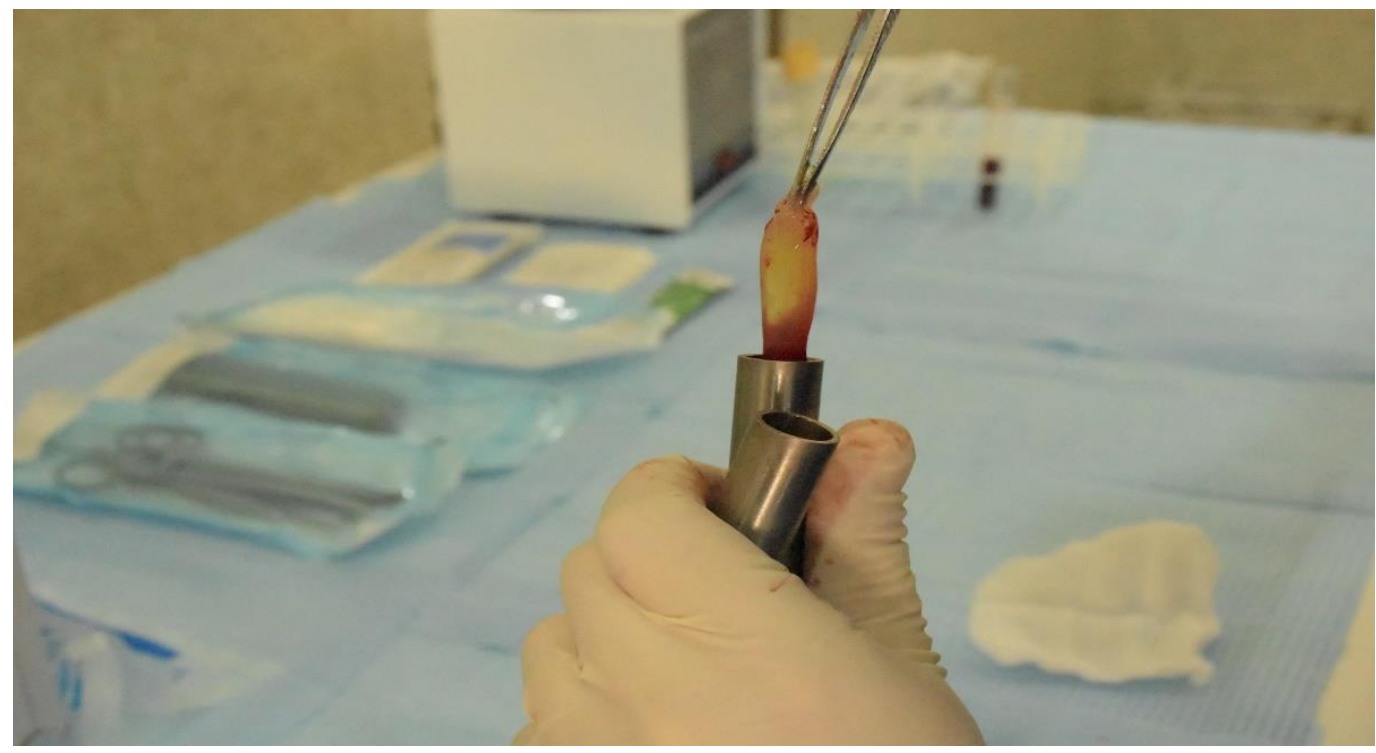

Fig. (1): platelet rich fibrin gel (3500 rpm/15mins).

Atropine sulphate (atrovap. Jordan) was given intramuscularly in a dose of $0.1 \mathrm{mg} / \mathrm{kg}$ body weight 10 minutes before induction of the anesthesia. All animals were operated on under general anesthesia induced by combination of xylazine (xyla. Interchemie Holland) in a dose of $0.2 \mathrm{mg} / \mathrm{kg}$ and ketamine hydrochloride (Ketalrom, romvac comp. Romania) in a dose of $22 \mathrm{mg} / \mathrm{kg}$ given intramuscularly. Lidocaine $2 \%$ (Laborale. India) was locally infiltered along the proposed lines of incision with infraorbital and mental nerve block.

On the day of operation, procaine penicillin and streptomycin sulphate combination (Pens \& strep norbrook. UK) was given intramuscularly in a dose of $24 \mathrm{mg} / \mathrm{kg}$ and $30 \mathrm{mg} / \mathrm{kg}$ respectively 1 hour before the operation and continued for 4 postoperative days.

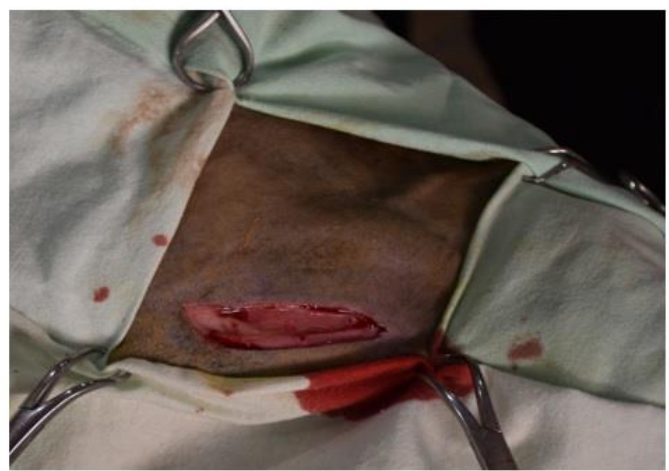

A
The animals were kept in lateral position and the surgical area was covered with sterile drapes. to expose the maxillary and mandibular bones, two skin incisions were made, $10 \mathrm{~cm}$ each, one over the lateral surface of maxillary bone (above and parallel to the facial tuberosity and below the infraorbital foramen) and the other one over the lateral aspect of the body of mandible. To create periosteal pockets, three periosteal incisions were made over each bone, each of $1 \mathrm{~cm}$ long and $1 \mathrm{~cm}$ apart, the periosteum was then elevated from the bone by periosteal elevators. The posterior periosteal pocket was filled with T-PRF membrane, the middle one was filled with L-PRF membrane, and the anterior pocket is left empty and considered as a control

Fig

(2).

Fig. (2): (A) incision in the maxillary area. (B) sub periosteal pockets. 
The periosteal incisions were closed by simple interrupted pattern and the subcutaneous tissue was closed with simple continuous pattern. Polyglycolic suture No.0 polypropylene.

Fourteen days later the same surgical procedure was performed for exposing the maxilla and mandible of the left side of face. The animals were kept in separate stalls and examined daily until removal of skin stitches at the $10^{\text {th }}$ postoperative day.

The animals were scarified and the samples were collected at day 14and 28 after the operation. The specimens were preserved in a $10 \%$ formaldehyde solution $24-72 \mathrm{~h}$ after extraction.

Histological processing for light microscopy

samples were taken from the sites that had been filled with T-PRF membranes and L-PRF were dehydrated in increasing gradients of alcohol $(70 \%, 95 \%$, and 100\%) and sited in toluene before paraffin inclusion. For each soft tissue sample, a series of 5 successive sections were achieved according to the long axis of the tissue. These sections were stained with haematoxylin and eosin.

\section{RESULTS}

We have found no significant differences between the samples on the fourteenth day (fig 3). While, on twenty-eight days when we compared the control, plastic and titanium histological sections we found that in case of plastic section more inflammation cells versus lesser inflammation cell in case of titanium section. on the other hand, fibrin cells where more organized and assemble in case of titanium histological section versus plastic ones, and we've seen that spaces between collagen bundles in case of plastic section due to silica particles effect

(fig.

4).

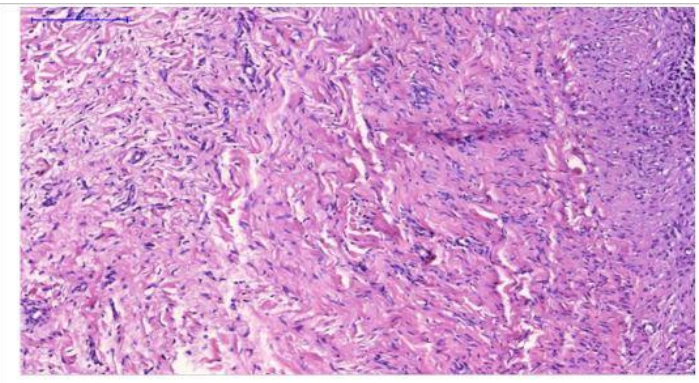

A

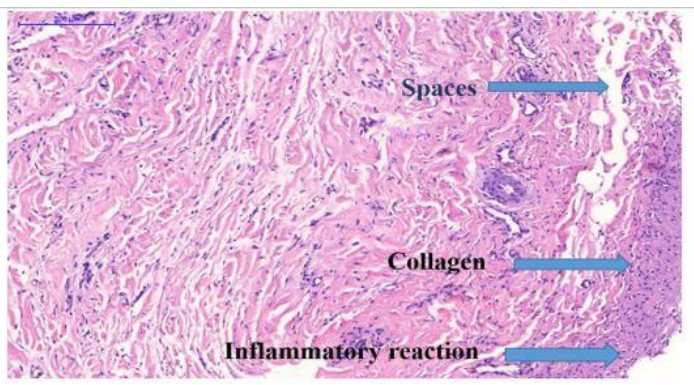

B

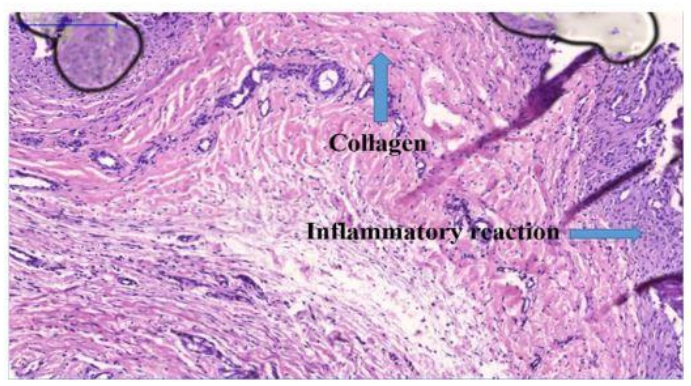

C

Fig. (3): (A) control group after 14 days. (B) PRF prepared in plastic tubes. (C) PRF prepared in titanium tubes. 


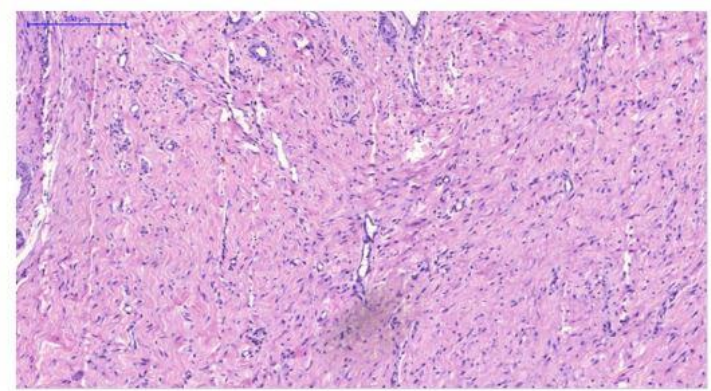

A

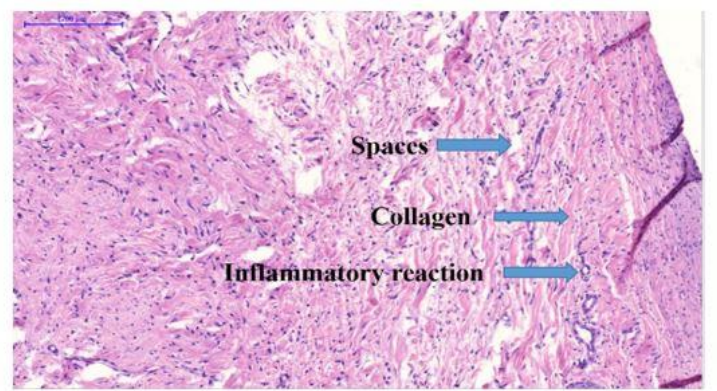

B

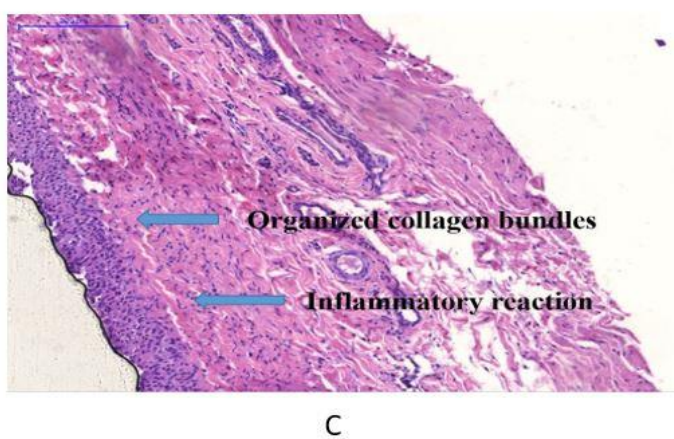

Fig. (4): (A) control group after 28 days. (B) PRF prepared with plastic tubes. (C) PRF prepared with titanium tubes.

\section{DISCUSSION}

This is a new platelet product that was able to form new connective tissue during the early stages of an in vivo study in rams. T-PRF used alone as a membrane formed new bone with connective tissue in the model of connective tissue wound healing in which regeneration was not expected in previous in vivo studies with Chouckroun's PRF in rabbits (Kim J-Y, He L et al 2010) the classic PRF protocol used in human subjects was not changed, and the material obtained was accepted as PRF. However, because it was not possible to obtain a sufficient amount of blood in a short period of time from a rabbit, which Dohan Ehrenfest e considered to be a rather small animal, it was necessary to attempt in vivo studies of PRF on larger animals. Dohan Ehrenfest had stated that the PRF-like product obtained from rabbits using the human protocol was not actually PRF, and that studies in rabbits would not produce accurate results. In our study in rams using the human PRF protocol to produce T-PRF, we encountered the same product described by Dohan Ehrenfest Based on this hypothesis, centrifugation of blood for 15 min at $3500 \mathrm{rpm}$ showed optimal characteristics of formation of fibrin based on observations using scanning EM (tunali et al 2013). Clinically mature T-PRF clots were seen in all test subjects (10 rams) the blood of which was centrifuged for $15 \mathrm{~min}$ at $3500 \mathrm{rpm}$. T-PRF had an effect in rams at least 28 days after insertion when used as a membrane. We are aware of working inside the oral cavity of rams due to limited mouth opening and may be impossible to get clean surgical incision without affect the sheep nutrition, so we had worked extra orally and it was more controlled and protected from contamination in this study. We had many subjects, even though 60 sections were obtained from the created pockets and imbedded membranes inside. We were not able to obtain quantitative results because the model could not be described as a bone wound healing model.

\section{CONCLUSIONS}

First, a T-PRF able to initiate and organize collagen fibers with minimum inflammatory reaction. Secondly, L-PRF also able to initiate collagen fibers with less amount and density due to spaces appearance which related to silica effect in the plastic tubes with much inflammatory reaction. 
the first in vivo application of T-PRF established it as a new platelet product that induced new connective tissue to form in as little as 14 days with excellent regenerative potential. T-PRF used alone as a membrane formed new bone with connective tissue in the wound healing model of connective tissue, in which regeneration was not expected. These results could lead to additional T-PRF animal and human studies of T-PRF in oral and maxillofacial surgery, implantology, and periodontology, and contribute to the understanding of this new platelet-rich product.

\section{REFERENCES}

Mustafa tunali, Hakan ozdemir et al. A Novel Platelet Concentrate: Titanium-Prepared Platelet-Rich Fibrin. http://dx.doi.org/10.1155/2014/209548

Anitua E, Sánchez M, Nurden AT, Nurden P, Orive G, Andia I. New insights into and novel applications for platelet-rich fibrin therapies. Trends Biotechnol 2006;24:227-34.

Choukroun J, Adda F, Schoeffler C, Vervelle A. An opportunity in perioimplantology: the PRF. Implantodontie 2001;42:55-62 [in French].

Dohan DM, Choukroun J, Diss A, et al. Platelet-rich fibrin (PRF): a second-generation platelet concentrate. Part I: technological concepts and evolution. Oral Surg Oral Med Oral Pathol Oral Radiol Endod 2006;101:e37-44.

Dohan DM, Choukroun J, Diss A, et al. Platelet-rich fibrin (PRF): a second-generation platelet concentrate. Part III: leucocyte activation: a new feature for platelet concentrates? Oral Surg Oral Med Oral Pathol Oral Radiol Endod 2006;101:e51-5.

Dohan Ehrenfest DM, Rasmusson L, Albrektsson T. Classification of platelet concentrates: from pure platelet-rich plasma (P-PRP) to leucocyte- and platelet-rich fibrin (L-PRF). Trends Biotechnol 2009;27:158-67.

Choukroun J, Diss A, Simonpieri A, et al. Plateletrich fibrin (PRF): a second-generation platelet concentrate. Part IV: clinical effects on tissue healing. Oral Surg Oral Med Oral Pathol Oral Radiol Endod 2006;101:e56-60.
Choukroun J, Diss A, Simonpieri A, et al. Plateletrich fibrin (PRF): a second-generation platelet concentrate. Part V: histologic evaluations of PRF effects on bone allograft maturation in sinus lift. Oral Surg Oral Med Oral Pathol Oral Radiol Endod 2006;101:299-303.

Del Corso M, Sammartino G, Dohan Ehrenfest DM. Re: Clinical evaluation of a modified coronally advanced flap alone or in combination with a platelet-rich fibrin membrane for the treatment of adjacent multiple gingival recessions: a 6-month study. J Periodontol 2009;80:1694-7.

Huang FM, Yang SF, Zhao JH, Chang YC. Plateletrich fibrin increases proliferation and differentiation of human dental pulp cells. $J$ Endod 2010;36:1628-32.

Sharma A, Pradeep AR. Autologous platelet rich fibrin in the treatment of mandibular degree II furcation defects: a randomized clinical trial. $J$ Periodontol 2011;82:1396-403.

Simonpieri A, Choukroun J, Del Corso M, Sammartino G, Dohan Ehrenfest DM. Simultaneous sinus-lift and implantation using microthreaded implants and leukocyte- and platelet-rich fibrin as sole grafting material: a six-year experience. Implant Dent 2011;20:212.

O'Connell SM, Impeduglia T, Hessler K, Wang XJ, Carroll RJ, Dardik H. Autologous platelet-rich fibrin matrix as cell therapy in the healing of chronic lower-extremity ulcers. Wound Repair Regen 2008;16:749-56.

Braccini F, Tardivet L, Dohan Ehrenfest DM. The relevance of Choukroun's Platelet-Rich Fibrin (PRF) during middle ear surgery: preliminary results. Rev Laryngol Otol Rhinol (Bord) 2009;130:175-80 [in French].

Baeyens W, Glineur R, Evrard L. The use of platelet concentrates: platelet-rich plasma (PRP) and platelet-rich fibrin (PRF) in bone reconstruction prior to dental implant surgery. Rev Med Brux 2010;31:521-7 [in French]. 
Inchingolo F, Tatullo M, Marrelli M. Trial with Platelet-Rich Fibrin and Bio-Oss used as grafting materials in the treatment of the severe maxillar bone atrophy: clinical and radiological evaluations. Eur Rev Med Pharmacol Sci 2010;14:1075-84.

Toffler M, Toscano N, Holtzclaw D. Osteotomemediated sinus floor elevation using only platelet-rich fibrin: an early report on 110 patients. Implant Dent 2010;19:447-56.

Gürbüzer B, Pikdöken L, Tunali M, et al. Scintigraphic evaluation of osteoblastic activity in extraction sockets treated with platelet-rich fibrin. J Oral Maxillofac Surg 2010;68:980-9.

O’Connell SM. Safety issues associated with plateletrich fibrin method. Oral Surg Oral Med Oral Pathol Oral Radiol Endod 2007;103:587-93.

Dohan EhrenfestDM,Diss A, Odin G, Doglioli P, HippolyteMP, Charrier JB. In vitro effects of Choukroun's PRF (platelet-rich fibrin) on human gingival fibroblasts, dermal prekeratinocytes, preadipocytes, and maxillofacial osteoblasts in primary cultures.
Oral SurgOral Med Oral Pathol Oral Radiol Endod 2009;108:341-52.

Lee E-H, Kim J-Y, Kweon HY, et al. A combination graft of lowmolecular- weight silk fibroin with Choukroun platelet-rich fibrin for rabbit calvarial defect. Oral Surg Oral Med Oral Pathol Oral Radiol Endod 2010;109:e33-8.

Dohan Ehrenfest DM, Del Corso M, Inchingolo F, Charrier JB. Selecting a relevant in vitro cell model for testing and comparing the effects of a Choukroun's platelet-rich fibrin (PRF) membrane and a platelet-rich plasma (PRP) gel: tricks and traps. Oral Surg Oral Med Oral Pathol Oral Radiol Endod 2010;110:409-11.

He L, Lin Y, Hu X, Zhang Y,Wu H. A comparative study of platelet-rich fibrin (PRF) and plateletrich plasma (PRP) on the effect of proliferation and differentiation of rat osteoblasts in vitro. Oral Surg Oral Med Oral Pathol Oral Radiol Endod 2009;108:707-13.

Kinlough-Rathbone RL, Rand M, Packham MA. Rabbit and rat platelets do not respond to thrombin receptor peptides that activate human platelets. Blood 1993;82:103-6. 